\title{
Computer-based methodology laboratories: 2. First-year graduate courses in data analysis
}

\author{
STANLEY H. COHEN \\ West Virginia University, Morgantown, West Virginia
}

\begin{abstract}
A graduate student microcomputer laboratory was set up with IBM PS/2 microcomputers to teach data analysis techniques in the first-year course sequence at West Virginia University. Microcomputer versions of SAS and SPSS statistical programs were incorporated into homework assignments. The lab was managed by a graduate assistant, and another graduate student provided consultation on software usage and homework problems. This shift from the use of mainframe to microcomputer statistical software allowed an increase in the number of assigned homework exercises and easier integration of statistical output into the writing of research reports.
\end{abstract}

In the Psychology Department at West Virginia University, a graduate student microcomputer laboratory has been established for instruction in data-analysis skills in the first-year research methods and data-analysis twocourse sequence. This microcomputer laboratory is not dedicated solely to instruction in methods, however; it also serves as a general departmental resource facility. Because these two purposes come together in the same laboratory, some issues general to the laboratory and some specific to the methods training will be described and discussed. These issues are related to the sections of this paper that follow: course objectives and format, hardware, software, user training, and lab management. The paper will conclude with an evaluation of the success of the laboratory in meeting instructional goals relative to the previous mode of instruction with the mainframe computer system.

\section{COURSE OBJECTIVES AND FORMAT}

All graduate students in the doctoral program in psychology are required to complete at least three semesters of research design and data analysis. The department therefore offers a two-semester course sequence that partially satisfies this requirement. The first course primarily covers complex experimental designs and related data analyses, usually analysis of variance (Keppel, 1982). The second course focuses on quasi-experimental and nonexperimental designs and related data analyses, simple and multiple correlation, and regression (Norusis, 1988). Course enrollments vary between 20 and 30 students. Lectures are given twice a week, each for $\mathbf{7 5} \mathrm{min}$. Extensive homework assignments are required throughout each

Funds to establish the microcomputer laboratory were provided by the College of Arts and Sciences, West Virginia University. Requests for copies of any instructional material should be sent to Stanley H. Cohen at the Department of Psychology, 104 Oglebay Hall, Morgantown, WV 26506-6040. semester. Homework is designed to give the student computational practice, to allow for the interpretation of statistical techniques and results, and to explore the consequences of different data-analytic strategies.

For many years, prior to the establishment of the microcomputer laboratory, students relied on a mainframe system to analyze homework data. Mainframe computer accounts were issued to each student at the beginning of the year. The students utilized both SAS and SPSS programs over the two semesters. A graduate teaching assistant and remote site consultants provided by the university's central computing center provided instructional support for the courses. The department housed four terminals with dial-up modems and a (slow) line printer, all connected to the mainframe computer. Line printers at several locations on campus provided additional facilities for printed output.

\section{HARDWARE}

Approximately 3 years ago, the department was given funds to develop a microcomputer laboratory for graduate students and faculty research and instruction. The lab was equipped with seven IBM PS/2 Model 50 machines, each with $1 \mathrm{MB}$ of RAM and a 20-MB fixed disk storage capacity, and one IBM PS/2 Model 80 machine with $1 \mathrm{MB}$ of RAM and a 40-MB hard disk drive. Output devices included two dot-matrix printers, one laser printer, and a six-pen flatbed plotter. Because many students personally owned older microcomputers, external 5.25-in. floppy disk drives were added to two machines.

A zero slot LAN by Alliance Network (Avatar Corporation, 1987) connected the microcomputers to all output devices and to a modem port for dial-up communication to the mainframe. The network has a star topology and includes software to configure each device and each computer on the LAN. The laboratory is available $24 \mathrm{~h}$ a day, 7 days a week through a security combination lock. 


\section{SOFTWARE}

The laboratory was designed to provide a variety of software, including word processing, graphics, database, and programming languages indigenous to the microcomputing realm. However, it became a means of gaining "independence" from the mainframe for statistical analysis. Microcomputer versions of SAS (SAS Institute, 1988) and SPSS (1989) with almost the same functionality as that of their mainframe versions were available for DOScompatible machines at "educational" prices. One major difference was that the user interface on the micro version of each program had a window interface that was "more friendly" than the command line scheme on the mainframe. On the other hand, the command language was virtually the same for both the mainframe and the microcomputer versions, which allowed the use of common reference manuals.

Students enrolled in the second course purchase a student version of SPSS (\$35) called Studentware (Norusis, 1988). This version is limited to 20 variables and does not contain some of the statistical procedures (e.g., nonparametric statistics, MANOVA) found in the regular package. However, the students own the software, and they can install it on their home microcomputer and work outside of the microlab. The Studentware package also includes a readable guide to data analysis and to the use of the software.

\section{TRAINING USERS}

At the beginning of the academic year, all first-year graduate students are given a 1-h orientation to the microlab by an advanced graduate student hired as the lab supervisor or manager. General instruction in using (and not abusing) disk drives, operating printers and changing paper, and diagnosing problems are included. The lab supervisor is on call during the semester to provide subsequent help.

An advanced graduate student is assigned to the graduate methods courses for the entire year as a teaching assistant for statistical consulting and handling computer analysis problems (e.g., Why is this a doubly repeated analysis of variance? How do I get PROC GLM in SAS to do a doubly repeated measures ANOVA?-and so forth). Students meet in small groups in the microlab and receive direct instruction in the use of the software as it relates to homework assignments.

A "graduated" series of homework assignments and problems has been developed for each course. Multiple regression, for example, has three associated microlab homework problems. The first assignment requires students to "merely" key in a previously constructed set of commands to produce a target analysis for discussion at the next lecture class. The second assignment requires students to generate a particular regression model and its summary statistics. The assignment concretely specifies the data set and the dependent and independent variables in the model, but not the command language necessary to produce output. The final assignment states data analysis objectives in general terms. The students must select appropriate variables to analyze, as well as a regression model.

The graduate assistant is on call to provide help outside of group sessions during office hours or by appointment. These one-on-one meetings appear to be especially helpful for students who continue to experience difficulties with either statistics or computers.

\section{MANAGEMENT}

The laboratory has been managed by a graduate student who not only provides general instruction to users but also is responsible for the day-to-day operation of the microlab. The lab manager keeps the equipment in working order (this includes especially the replacement of printer ribbons and paper), remakes hard disks that become cluttered with user files, and troubleshoots problems arising from software/hardware incompatibility.

During the first 2 years of operation, the laboratory has developed a printed set of procedures that is distributed during the orientation session. This year, the microlab published a newsletter twice each semester, which contained announcements about new software, complaints about old, unsolved problems, and helpful hints for users. The content of the newsletters will be incorporated into future editions of the procedure manual.

In order to provide computing power and flexibility, RAM has been increased to $4 \mathrm{MB}$ on two machines. A second fixed disk drive (40 MB) allows for a larger variety of limited-use software on at least one computer.

\section{EVALUATION}

To judge from personal observation, student comments, and course evaluations, the microlaboratory has exceeded the department's initial expectations with respect to usage and utility. A large percentage of the statistical computing related to coursework, theses, and dissertations is now conducted in the lab. Turnaround time and convenience have led to this result. The first-year methodology courses appear to run more smoothly and without "crises" resulting from mainframe down time. In fact, the number of homework exercises assigned in each course has increased about $25 \%$.

The microcomputer environment is more friendly than the mainframe environment to students taking the firstyear course sequence. These students spend considerably less time learning how to "get on the computer"' and become more involved with the content of data analysis. The atmosphere in the microcomputer lab encourages peer tutoring, since several students often work on assignments at the same time in the lab.

Statistical computing on a microcomputer system also integrates well with other stages in the research process, especially the writing of research reports. Students are 
encouraged to save their statistical "printouts" into disk files. These files can be imported by word processing programs and edited into final tables and figures. Several homework assignments involve writing an APA-style Results section based on the homework analyses.

Users of the microcomputer version of the statistical software can still access the mainframe. Both SAS and SPSS allow easy transfer of programs and data between different versions. SAS data files are identical for both platforms, and SPSS uses portable data files.

Some problems remain. Students can no longer rely on the mainframe computer center services to manage and back up files. Students are warned about backing up to safeguard their work, but inevitably one or two lose their work at some time during the semester. The lab manager can help recover some lost work, using utility software such as Norton Utilities (Symantec, 1990) or PC Tools (Central Point Software, 1990). A fixed schedule for the lab manager and course assistant has helped to provide consultation on a regular basis. Finally, because the cost of paper, ribbons, and laser toner cartridges has soared, the department has established a nominal chargeback on print volume. It is still too early to determine the effectiveness of the collection procedure.

Shifting our graduate methods teaching emphasis from the mainframe to the microcomputer has resulted in remarkable benefits similar to those realized in the earlier transformation from calculating machine to mainframe computer (Cooley \& Lohnes, 1962; Green, 1963). Increases in productivity and interaction have been the major outcomes.

\section{REFERENCES}

Avatar CORPoration. (1987), Alliance network guide (Computer manual]. Hopkinton, MA: Author.

Central Point Software. (1990). PC tools deluxe (Version 6.0) [Computer program]. Beaverton, OR: Author.

COOLEY, W. W., LOHNES, P. R. (1962). Multivariate procedures for the behavioral sciences. New York: Wiley.

GREEN, B. F., JR. (1963). Digital computers in research: An introduction for behavioral and social scientists. New York: McGrawHill.

KEPPEL, G. (1982). Design and analysis: A researcher's handbook (2nd ed.). Englewood Cliffs, NJ: Prentice-Hall.

Norusis, M. J. (1988). SPSS/PC+ studentware [Computer manual]. Chicago: SPSS, Inc.

NoRUSIs, M. J. (1988). SPSS-X introductory statistics guide (SPSS-X Release 3) [Computer manual]. Chicago: SPSS.

SAS INSTITUTE, INC. (1988). SAS introductory guide for personal computers (Release 6.03). [Computer manual]. Cary, NC: Author.

SPSS, INC. (1989). SPSS/PC + update for v 3.0 and v 3.1 [Computer manual]. Chicago: Author.

Symantec Corporation. (1990). The Norion utilities (Version 5.0) [Computer program]. Cupertino, CA: Author. 